\title{
Effects of laser treating on surface morphology of MAO coating on AZ91 magnesium alloy
}

\author{
Yunlong Wang ${ }^{1, a,{ }^{*}}$, Linzhong Zhu ${ }^{1, b}$, Yang Sheng ${ }^{1, c}$, Caiyan Chen ${ }^{1, d}$, Zhicheng \\ Liu $^{1, e}$ Weixing Ren ${ }^{1, f}$, Guohao Cheng ${ }^{1, g}$ \\ ${ }^{1}$ School of Materials Science and Engineering, Jiangsu University, Zhenjiang, 212013,China \\ aWangyunlong@ujs.edu.cn (Corresponding author \\ Email), 'Vernon2012@sina.cn, 'CShengy@ujs.edu.cn, ${ }^{\mathrm{d}}$ Chency@ujs.edu.cn \\ éLiuzc@ujs.edu.cn, ${ }^{\mathrm{f}}$ Renwx@ujs.edu.cn, ${ }^{9}$ Chenggh@ujs.edu.cn
}

Keywords: Laser treating; Surface morphologies; MAO coating; Biomedical magnesium alloy

\begin{abstract}
Micro arc oxidation (MAO) coating was first fabricated on AZ91 biomedical magnesium alloy and followed by surface laser treating. Effects of laser treating on surface characteristics of MAO coating were studied. The results indicated that after surface laser treating, the micro pores on MAO coating surface became fewer and smaller. The whole surface became more unique and compact. The surface quality of MAO coating was improved.
\end{abstract}

\section{Introduction}

Recently, biomedical magnesium alloy has received much attention with the increasing of care of health paid on human beings [1-2]. It is one of the lightest metal with excellent physical and mechanical properties such as low density, high specific strength and good castability [3-4]. Unfortunately, biomedical magnesium alloy has poor corrosion resistance when were utilized in actual conditions because of their relatively low chemical stability and high negative potential [5]. Therefore, many methods have been developed to offer protection for biomedical magnesium alloy, among which, the surface modification technique of micro arc oxidation (MAO) has become a frequently used method in recent years [1, 3-4]. MAO can prepare corrosion resistance ceramic coatings on $\mathrm{Mg}$ and other metals surface through plasma charge in anodic electrolytic process. The corrosion resistance of the biomedical magnesium alloys can be increased with MAO coating on the surface [6-7]. However, it is also the plasma charge during MAO that makes MAO tends to produce a porous surface of these metals and even with some micro cracks or crater-shape discharge channels. Corrosive species can penetrate easily through these surface defects to corrode the substrate [8-9]. Therefore, many post treatments such as sol-gel coating and rare earth sealing are gradually developed to further improve the corrosion resistance of the MAO coating on metals surface.

The aim of present paper is to develop a method of surface laser treating as a new route to further improve the surface quality of MAO coating on biomedical magnesium alloys. Effects of laser treating on surface characteristics and corrosion resistance of MAO coating on AZ91 in simulated body fluids (SBF) were studied. As expected, a satisfactory result was obtained that surface laser treating of MAO coating could decrease the surface defects of MAO coating and further increased the corrosion resistance of AZ91 biomedical magnesium alloy in SBF.

\section{Experimental procedure}

\section{MAO treatment}

AZ91 alloy with the chemical compositions of Al 8.3-9.7, Zn 0.35-1.0, Mn 15-0.50, $\mathrm{Si}<0.01$, $\mathrm{Cu}<0.03, \mathrm{Ni}<0.002, \mathrm{Fe}<0.005$, was cut into pie shape with size of $\Phi 15 \mathrm{~mm} \times 0.5 \mathrm{~mm}$ thickness. The sample was first grounded and polished and then served as anode during MAO treatment. The electrolyte system was a optimized electrolyte containing proper concentration of $\mathrm{Na}_{3} \mathrm{PO}_{4}$, $\mathrm{Na}_{2} \mathrm{SiO}_{3}, \mathrm{NaOH}$ and glycerinum. During MAO treatment, a bi-pole power source was used and the 
current densities of anode and cathode were kept constant at $10 \mathrm{~A} / \mathrm{dm}^{2}$ and $4 \mathrm{~A} / \mathrm{dm}^{2}$, respectively; the pulse frequency was kept $3000 \mathrm{~Hz}$; duty ratio 50\% the treating time was $10 \mathrm{~min}$.

\section{Laser treatment}

A Nd:YAG Nanosecond pulse laser (Precision II 8010, USA) was used to treat the MAO coating surface. The wavelength of Nanosecond laser was 532nm; the pulse duration was about 6-8ns. The pulse frequency was $10 \mathrm{~Hz}$. The pulse output energy is adjustable. Focal length of the focus lens is $35 \mathrm{~mm}$, and the diameter of the spots is $1.75 \mathrm{~mm}$. During the treatment, the coating surface was scanned by laser from the top surface to bottom surface for several times to obtain a optimized surface of the coating.

\section{Surface morphology characterization}

The morphology of the MAO coatings before and after surface laser treating were investigated by scanning electron microscopy (SEM, S-3400N, Hitachi, Japan ).

\section{Results and discussion}

Surface Morphologies. Figure 1 is the rough sketch of laser treated and untreated area on samples. The light area is laser treated region and the dark area is the untreated region. Figure 2

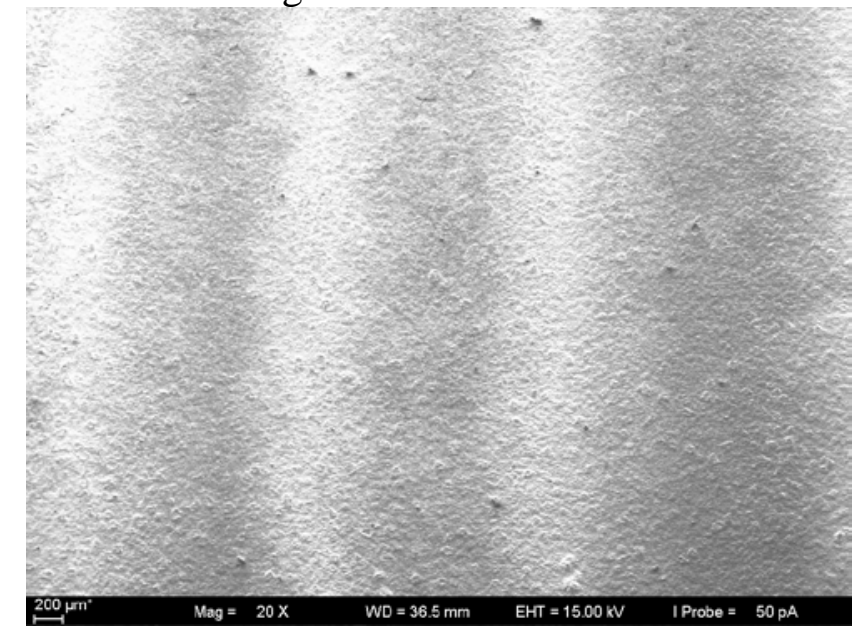

Figure 1 rough sketch of laser treated and untreated area

Shows the details of laser treated and untreated area. Figure 2 (a) and (c) are photos in low magnification with the 500 magnification and Figure 2 (b) and (d) are photos in high magnification with the 2000 magnification. Figure 2 (a) reveals that coating without laser treating exhibits typical porous and course surface of MAO. There are some pores whose diameters are larger than $10 \mu \mathrm{m}$. These micro pores are formed during the discharges reaction during the MAO and the big pores are resulted form the intense discharge in local micro area. Figure 2 (c) shows that as a whole, the coating surface becomes more unique after surface laser treating. Figure 2 (d) further indicates that the big pores on the surface are turn into small ones which are about $4-5 \mu \mathrm{m}$. Therefore, it can be concluded that laser treating of MAO coating can improve the surface quality of MAO coating. 

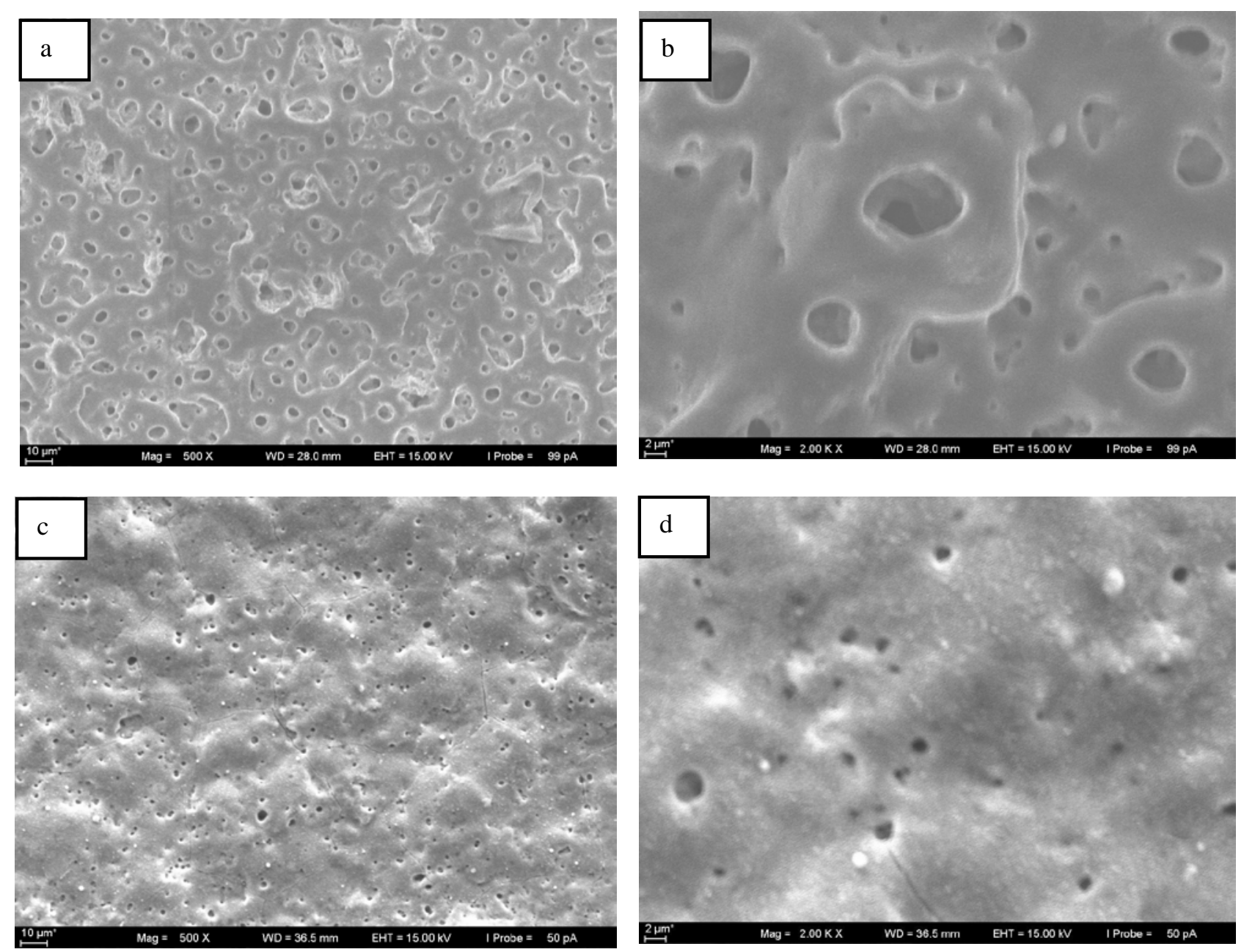

Figure 2 Surface morphologies of MAO coatings on AZ91 alloy before $(a, b)$

and after laser treating (c, d)

\section{Conclusions}

Micro arc oxidation coating was first prepared on AZ91 biomedical magnesium alloy and then the coating surface was subjected to laser treating. By surface laser treating, the micro pores on the MAO coating surface became fewer and smaller. The whole surface became more unique and compact. The surface quality of MAO coating was improved.

\section{Acknowledgements}

This work was supported by 'A Project Funded by the Priority Academic Program Development of Jiangsu Higher Education Institutions', the Natural science fund for colleges and the Natural Science Foundation of Jiangsu Province (BK20130509) and the Natural science fund for colleges and universities in Jiangsu Province (12KJB430005). The corresponding author is Yunlong Wang, Tel/fax:86-511-88790191, E-mail:wangyunlong@ujs.edu.cn.

\section{References}

[1] D. Veys-Renaux, E. Rocca, J. Martin, G. Henrion, Initial stages of AZ91 Mg alloy micro-arc anodizing: Growth mechanisms and effect on the corrosion resistance, Electrochim. Acta. 124 (2014) 36-45.

[2] M.P. Neupane, S.J. Lee, J.Y. Kang, I.S. Park, T.S. Bae, M.H. Lee, Surface characterization and corrosion behavior of silanized magnesium coated with graphene for biomedical application, Mater. 
Chem. Phys. 163 (2015) 229-235.

[3] L.C. Zhao, C.X. Cui, X. Wang, S.J. Liu, S.J. Bu, Q.Z. Wang, Y.M. Qi, Corrosion resistance and calcium-phosphorus precipitation of micro-arc oxidized magnesium for biomedical applications, App. Surf. Sci. 330 (2015) 431-438.

[4] A. Dey, R. Umarani, H. K. Thota, P. Bandyopadhyay, A. Rajendra, A. K. Sharma, A. K. Mukhopadhyay, Corrosion and nanoindentation studies of MAO coatings, surf. Eng. 30 (2014) 913-919.

[6] Y.M. Wang , J.W. Guo, Z.K. Shao, J.P. Zhuang, M.S. Jin, C.J. Wu, D.Q. Wei, Y. Zhou, A metasilicate-based ceramic coating formed on magnesium alloy by microarc oxidation and its corrosion in simulated body fluid, Surf. Coat. Technol. 219 (2013) 8-14.

[7] C.L. Chu , X. Han, J. Bai, F. Xue, P. Chu, Surface modification of biomedical magnesium alloy wires by micro-arc oxidation, Trans. Nonferrous Met. Soc. China. 24 (2014) 1058-1064.

[8] J. Liang, P. Bala Srinivasan, C. Blawert, M. Störmer, W. Dietzel, Electrochemical corrosion behaviour of plasma electrolytic oxidation coatings on AM50 magnesium alloy formed in silicate and phosphate based electrolytes, Electrochim. Acta. 54 (2009) 3842-3850.

[9] C.L. Chu , X. Han, F. Xue, J. Bai, P.K. Chu, Effects of sealing treatment on corrosion resistance and degradation behavior of micro-arc oxidized magnesium alloy wires, Appl. Surf. Sci. 271 (2013) 271-275. 